Supporting Information

\title{
NiFe LDH/MXene Derivatives Interconnected Carbon Fabric for Flexible Electromagnetic Wave Absorption
}

Zihan Wang ${ }^{a}$, Liuxin Yang ${ }^{b}$, Yang Zhou ${ }^{b}$, Chen Xu ${ }^{b}$, Mi Yan and Chen $W u^{a, *}$

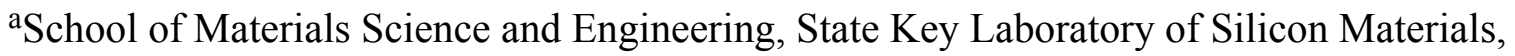
Zhejiang University, Hangzhou 310027, China

' Institute of Materials, China Academy of Engineering Physics, Jiangyou 621908, China

*Corresponding author: chen_wu@zju.edu.cn

Since the $\mathrm{Ti}_{3} \mathrm{C}_{2} \mathrm{~T}_{\mathrm{x}}$ MXene was firstly exfoliated from MAX phase and then collected and dried, it restacks into each other and forms the morphology as shown in Figure S1. In the fabrication process for the NiFe $\mathrm{LDH} / \mathrm{MX}$ ene however, the exfoliated MXene is dispersed in the solution without collecting and drying. The growth of the NiFe LDH nanosheets on the surfaces of the MXene avoid restacking as shown in Figure $1 \mathrm{~b}$ in the manuscript. 


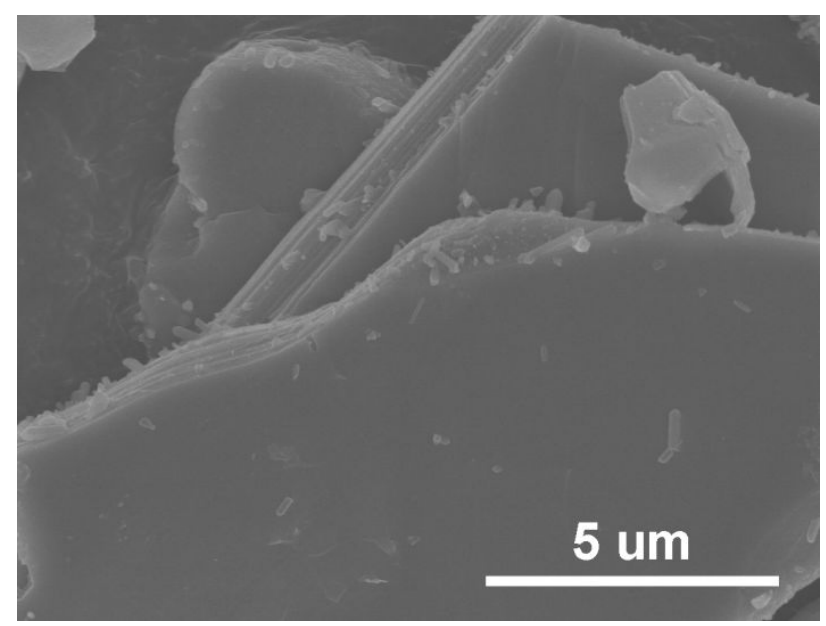

Figure S1. SEM image of exfoliated MXene.

Flexibility of M3 sample was also tested and a bending angle up to $180^{\circ}$ demonstrated in Figure S2.

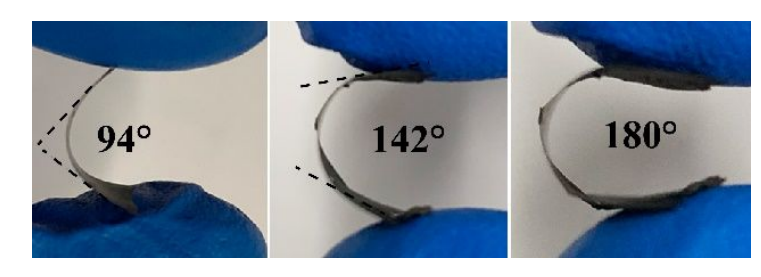

Figure S2. Different bending angles of M3 with satisfactory flexibility.

$\mathrm{NiFe}$ LDH/MXene has been calcinated through the same route without the addition of the PAN. As shown in the XRD data in Figure $\mathrm{S} 3, \mathrm{NiO}$ and $\mathrm{Fe}_{2} \mathrm{O}_{3}$ are formed after calcination instead of the $\mathrm{FeNi}_{3}$, confirming the reduction effect of the carbon fibers. The reaction courses of NiFe LDH/MXene with PAN and without PAN could be inferred as follows:

$$
\begin{gathered}
\mathrm{NiFe} \mathrm{LDH}+\mathrm{C} \rightarrow \mathrm{FeNi}_{3}+\mathrm{CO}_{2}+\mathrm{H}_{2} \mathrm{O} \\
\mathrm{NiFe} \mathrm{LDH} \rightarrow \mathrm{Fe}_{2} \mathrm{O}_{3}+\mathrm{NiO}+\mathrm{H}_{2} \mathrm{O}
\end{gathered}
$$

The network structure has been maintained after calcination, during which such contact is 
beneficial for the reduction of the NiFe $\mathrm{LDH} / \mathrm{MXene}$ into $\mathrm{FeNi}_{3} / \mathrm{TiO}_{2}$ with the assistance of the PAN fibers. The reduction should have occurred at the interface between the $\mathrm{NiFe}$ LDH/MXene and the carbon fibers.

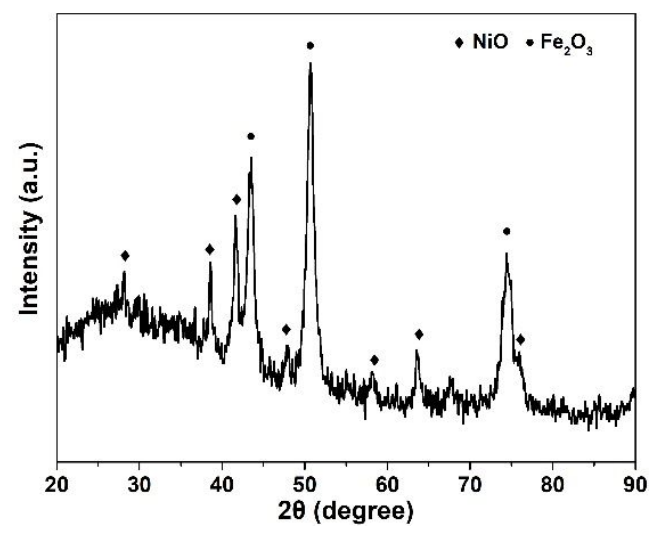

Figure S3. XRD pattern of calcinated NiFe LDH/MXene without PAN.

Figure S4 shows SEM images taken from the M1, M2 and M4 before and after calcination.

Similar to the M3, the fiber structure is preserved for all the other samples.

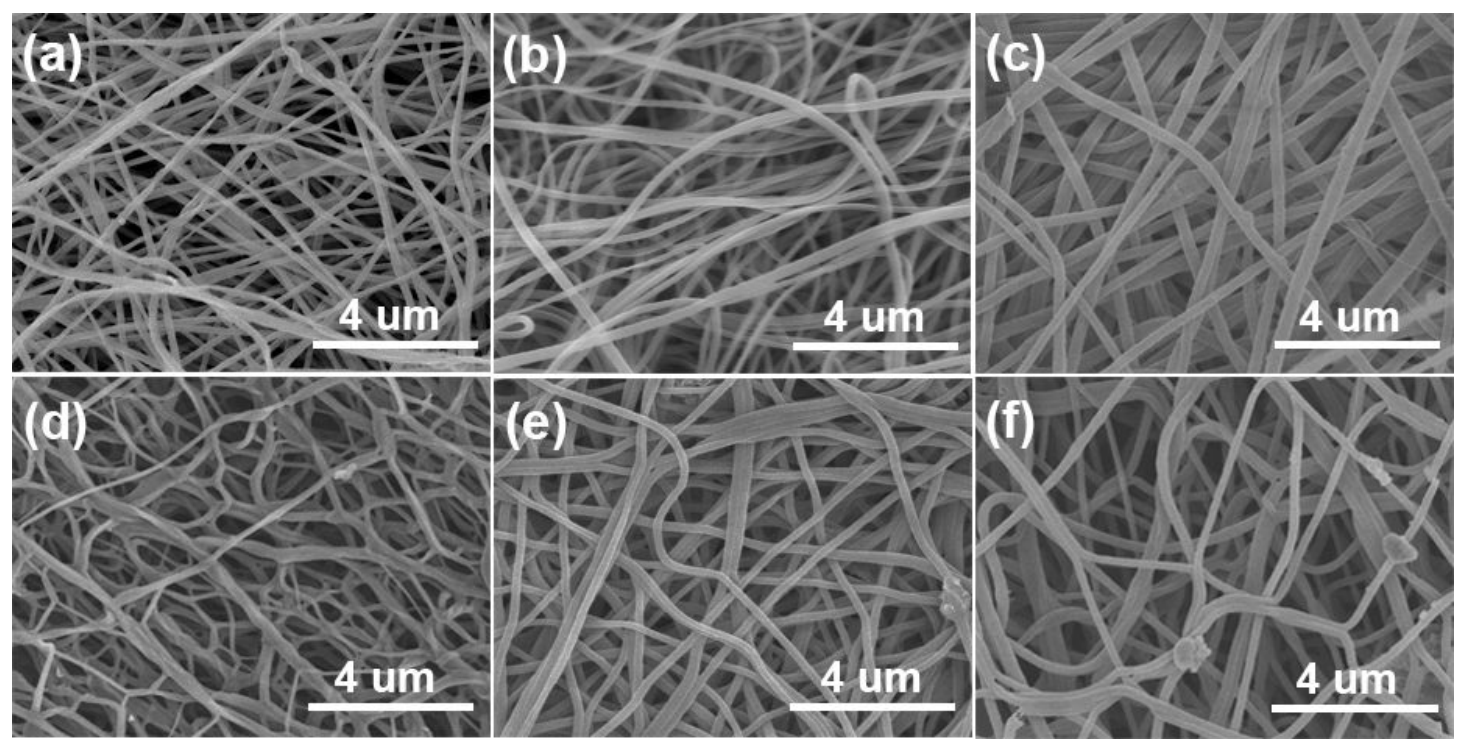

Figure S4. (a-c) SEM images of M1, M2, and M4 before calcination. (d-e) SEM images of M1, M2 and M4 after calcination. 
Figure S5 shows the Energy Dispersive Spectroscopy (EDS) mappings of the $\mathrm{FeNi}_{3} / \mathrm{TiO}_{2}$ flakes. It can be seen that the $\mathrm{Fe}$ and $\mathrm{Ni}$ are uniformly distributed on the on the $\mathrm{TiO}_{2}$ surface, resulting in enhanced conductivity of the composite flakes.

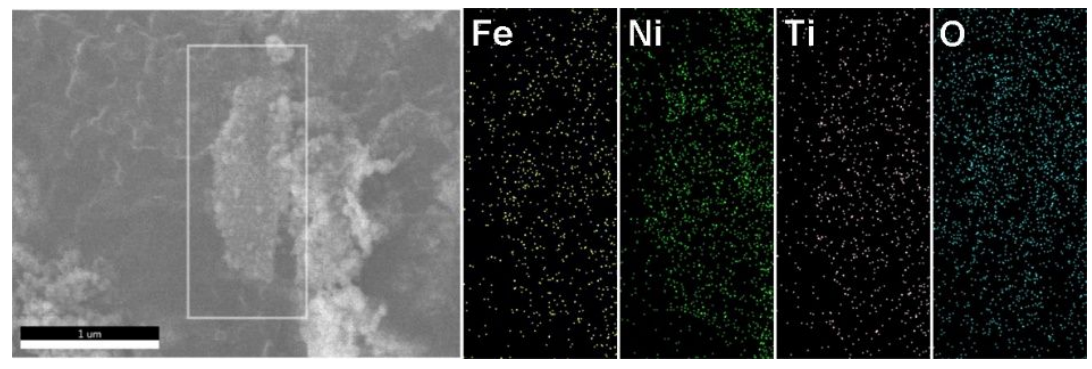

Figure S5. EDS mappings showing the distribution of the $\mathrm{Fe}, \mathrm{Ni}$, $\mathrm{Ti}$ and $\mathrm{O}$ of the $\mathrm{FeNi}_{3} / \mathrm{TiO}_{2}$ flakes.

Raman spectra of M3 and carbon fiber alone have been tested to study the carbonization degree of carbon fiber. It can be seen in Figure $S 6$ that the value of $I_{D} / I_{G}$ of $M 3$ is smaller than the one of carbon fiber alone, indicating the higher carbonization degree of M3.

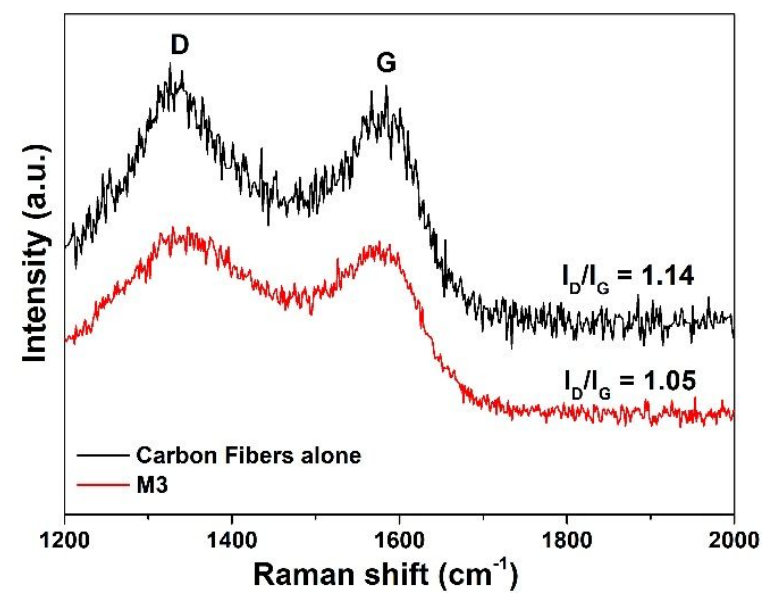

Figure S6. Raman spectra of M3 and carbon fiber alone.

XPS spectrum of the $\mathrm{O}_{1 \mathrm{~s}}$ and $\mathrm{C}_{1 \mathrm{~s}}$ peaks for the $\mathrm{M} 3$ can be deconvoluted into O-Ti, O-Fe and O-Ni peaks as well as C-C and C-Ti peaks as shown in Figure S7. Due to the small content and embedment of the $\mathrm{FeNi}_{3} / \mathrm{TiO}_{2}$ flakes in the carbon fibers, the signal of $\mathrm{Ni}_{2 \mathrm{p}}$, 
$\mathrm{Fe}_{2 \mathrm{p}}$, and $\mathrm{Ti}_{2 \mathrm{p}}$ peaks are subtle.
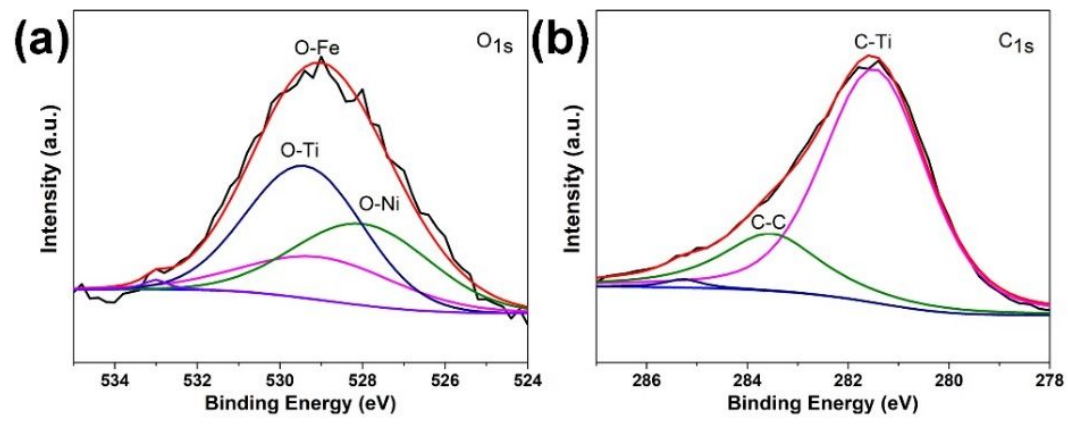

Figure S7. XPS spectra of the (a) $\mathrm{O}_{1 \mathrm{~s}}$ and (b) $\mathrm{C}_{1 \mathrm{~s}}$ peaks for the M3.

As seen in Figure S8, similar trends have been obtained for the TG curves of the two samples with a loss platform from $127^{\circ} \mathrm{C}$ to $277^{\circ} \mathrm{C}$ due to the transformation of PAN from liner to ladder structure. ${ }^{1}$ Between $300{ }^{\circ} \mathrm{C}$ and $650{ }^{\circ} \mathrm{C}$, dramatic weight loss takes place during the carbonization process. After calcination, $47.3 \mathrm{wt} \%$ of the original weight is maintained for the PAN fibers compared to $49.0 \mathrm{wt} \%$ for the NiFe LDH/MXene PAN fibers. Consequently, the $95.0 \mathrm{wt} \%$ PAN contained in the NiFe LDH/MXene PAN evolves into $95.0 \mathrm{wt} \% \times 47.3 \%=44.9 \mathrm{wt} \%$ carbon fibers after calcination, while the $5.0 \mathrm{wt} \% \mathrm{NiFe}$ $\mathrm{LDH} / \mathrm{MXene}$ transforms into $49.0 \mathrm{wt} \%-44.9 \mathrm{wt} \%=4.1 \mathrm{wt} \% \mathrm{FeNi}_{3} / \mathrm{TiO}_{2}$, for which 82.1 $w t \%$ of its original weight is remained. Based on the remaining weight of the PAN fibers (47.3 wt $\%$ ) and $\mathrm{NiFe}$ LDH/MXene (82.1 wt\%) after calcination, the weight ratio of carbon fiber and $\mathrm{FeNi}_{3} / \mathrm{TiO}_{2}$ in the calcinated PAN with $3.0 \mathrm{wt} \%$ and $7.0 \mathrm{wt} \% \mathrm{NiFe} \mathrm{LDH} / \mathrm{MXene}$ can be estimated. Take the $3.0 \mathrm{wt} \% \mathrm{NiFe} \mathrm{LDH} / \mathrm{MXene}$ PAN fibers as an example, $3.0 \mathrm{wt} \%$ $\mathrm{NiFe} \mathrm{LDH} / \mathrm{MX}$ ene transits into $3.0 \mathrm{wt} \% \times 82.1 \%=2.5 \mathrm{wt} \%$ of $\mathrm{FeNi}_{3} / \mathrm{TiO}_{2}$ while $97.0 \mathrm{wt} \%$ PAN became $97.0 \mathrm{wt} \% \times 47.3 \%=45.9 \mathrm{wt} \%$ of carbon fibers, from which the weight ratio of $\mathrm{FeNi}_{3} / \mathrm{TiO}_{2}$ is $2.5 \mathrm{wt} \% /(2.5 \mathrm{wt} \%+45.9 \mathrm{wt} \%)=5.1 \mathrm{wt} \%$ and that of the carbon fibers is $100.0 \mathrm{wt} \%-5.1 \mathrm{wt} \%=94.9 \mathrm{wt} \%$. The weight ratio of $\mathrm{FeNi}_{3} / \mathrm{TiO}_{2}$ and carbon fibers in the other sample has been calculated in the same way as shown in Table S1. In the preparation of the final test circular sample, $50.0 \mathrm{wt} \%$ sample was mixed with $50.0 \mathrm{wt} \%$ 
paraffin, so the content of each component in the circular paraffin sample could be calculated as in Table S2.
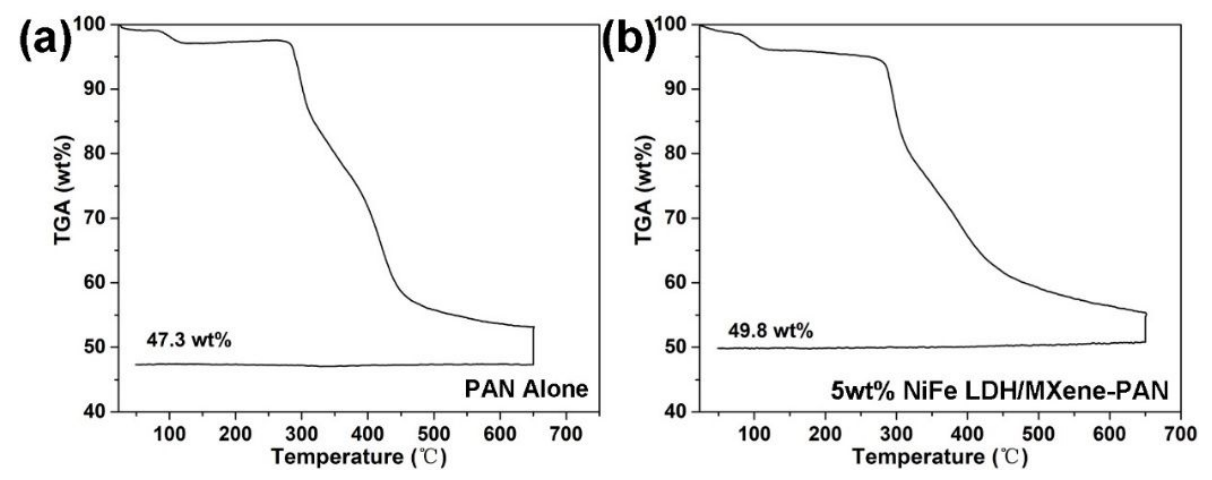

Figure S8 TG analysis of (a) the PAN fibers alone and (b) those containing $5 \mathrm{wt} \% \mathrm{NiFe}$ LDH/MXene.

Table S1. Weight ratio estimated for the $\mathrm{FeNi}_{3} / \mathrm{TiO}_{2}$ and carbon fibers for $\mathrm{M} 1$ - $\mathrm{M} 3$.

\begin{tabular}{|c|c|c|}
\hline & $\mathbf{F e N i}_{3} / \mathbf{T i O}_{\mathbf{2}}$ (wt $\left.\%\right)$ & Carbon Fibers (wt\%) \\
\hline $\mathbf{M 1}$ & 5.1 & 94.9 \\
\hline $\mathbf{M} 2$ & 8.4 & 91.6 \\
\hline M3 & 11.6 & 88.4 \\
\hline
\end{tabular}

Table S2. Weight ratio of $\mathrm{FeNi}_{3} / \mathrm{TiO}_{2}$ and carbon fibers with the addition of paraffin.

\begin{tabular}{|l|c|c|c|}
\hline & $\mathbf{F e N i}_{\mathbf{3}} / \mathbf{T i O}_{\mathbf{2}} \mathbf{( w t \% )}$ & Carbon Fibers (wt \%) & Paraffin (wt\%) \\
\hline M1-Paraffin & 2.6 & 47.4 & 50.0 \\
\hline M2-Paraffin & 4.2 & 45.8 & 50.0 \\
\hline M3-Paraffin & 5.8 & 44.2 & 50.0 \\
\hline
\end{tabular}

Figure S9a shows the XRD pattern of carbon fabric with the addition of NiFe LDH, which transits into $\mathrm{Fe}$ and $\mathrm{Ni}$ after calcination. Figure S9b and S8c are TEM images showing small particles of $\mathrm{Fe}$ and $\mathrm{Ni}$ incorporated inside the carbon fibers. 

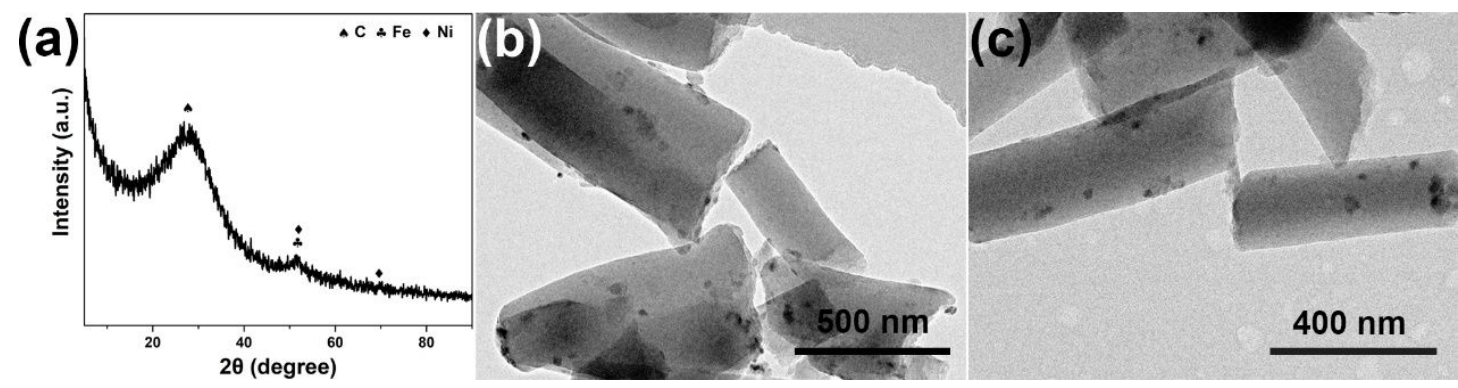

Figure S9. (a) XRD pattern and (b-c) TEM images for the carbon fabric with the addition of NiFe

LDH.

Figure S10a-c shows $\varepsilon^{\prime}, \varepsilon^{\prime \prime}$ and $\tan \varepsilon$ of the carbon fabric and that with NiFe LDH addition compared to those of the M3. Larger $\varepsilon^{\prime}, \varepsilon^{\prime \prime}$ and $\tan \varepsilon$ are observed for the M3 compared with the carbon fabric and the sample with the addition of NiFe LDH. The M3 exhibits the enhanced attenuation and impedance matching (Figure S10d-f), giving rise to improved reflection loss (RL) as in Figure S10g-i.
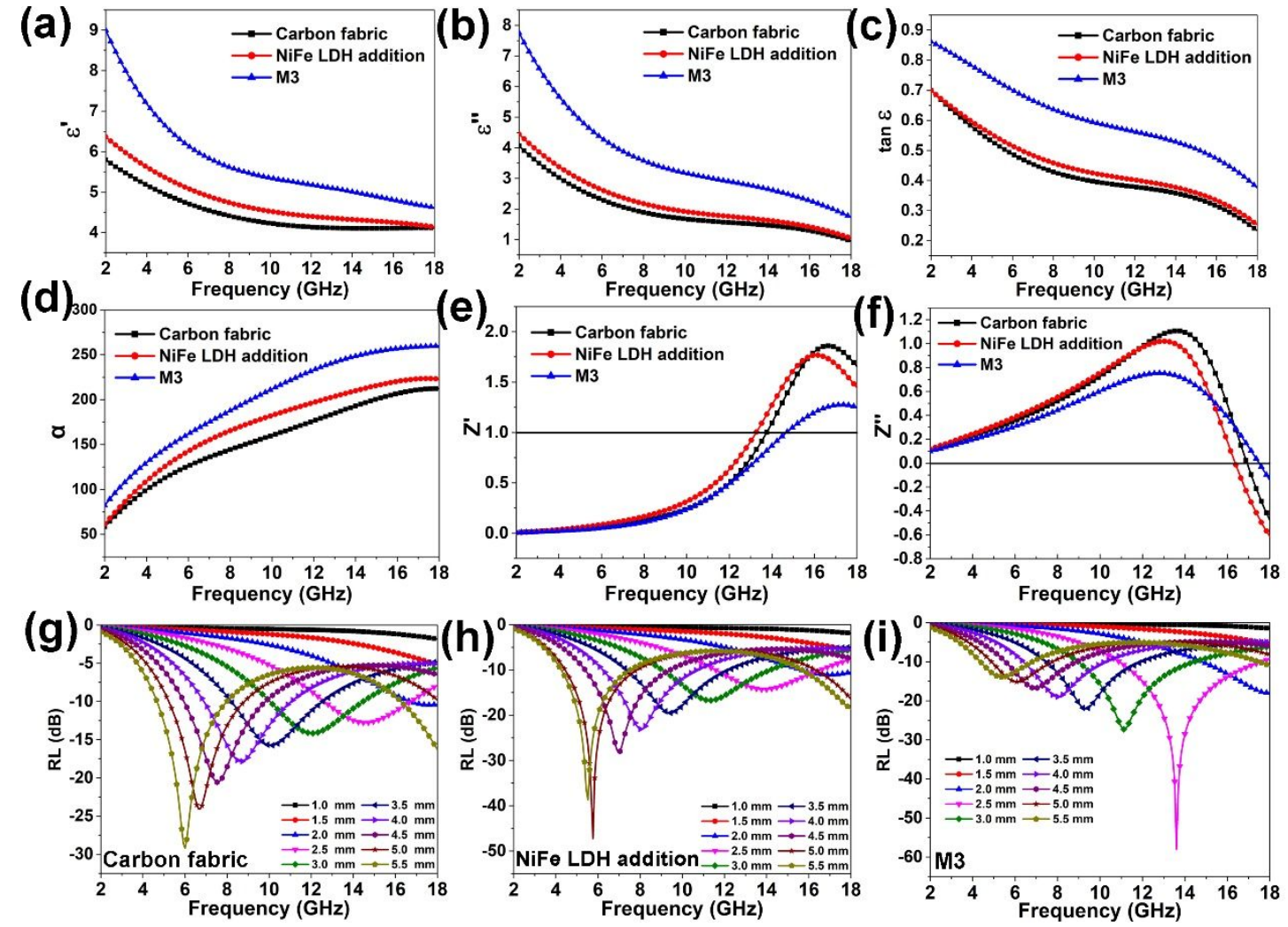

Figure S10. (a-c) $\varepsilon^{\prime}, \varepsilon^{\prime \prime}$ and $\tan \varepsilon$ of the carbon fabric, sample with the addition of NiFe LDH and 
M3. (d-f) Attenuation constant ( $\alpha$ ), real ( $\left.Z^{\prime}\right)$ and imaginary $\left(Z^{\prime \prime}\right)$ impedance as well as the (g-i) reflection Loss (RL) of different samples.

As shown in Figure $\mathrm{S} 11$, the $\mathrm{FeNi}_{3} / \mathrm{TiO}_{2}$ exhibit higher $\varepsilon^{\prime}, \varepsilon^{\prime \prime}$ and tan $\varepsilon$ as well as larger $\mu^{\prime}, \mu^{\prime \prime}$ and $\tan \mu$ than those of the NiFe LDH/MXene due to the higher conductivity and magnetization of the $\mathrm{FeNi}_{3}$. The higher dielectric loss and magnetic loss of $\mathrm{FeNi}_{3} / \mathrm{TiO}_{2}$ contribute to stronger dissipation than the NiFe LDH/MXene as shown in Figure S11g. Better impedance matching is also achieved in the $\mathrm{FeNi}_{2} / \mathrm{TiO}_{2}$, resulting in better absorption performance $(\mathrm{RL}=-14.9 \mathrm{~dB}$ at $17.0 \mathrm{GHz})$ than the $\mathrm{NiFe} \mathrm{LDH} / \mathrm{MXene}(\mathrm{RL}=-$ $7.9 \mathrm{~dB}$ at $14.9 \mathrm{GHz})$.
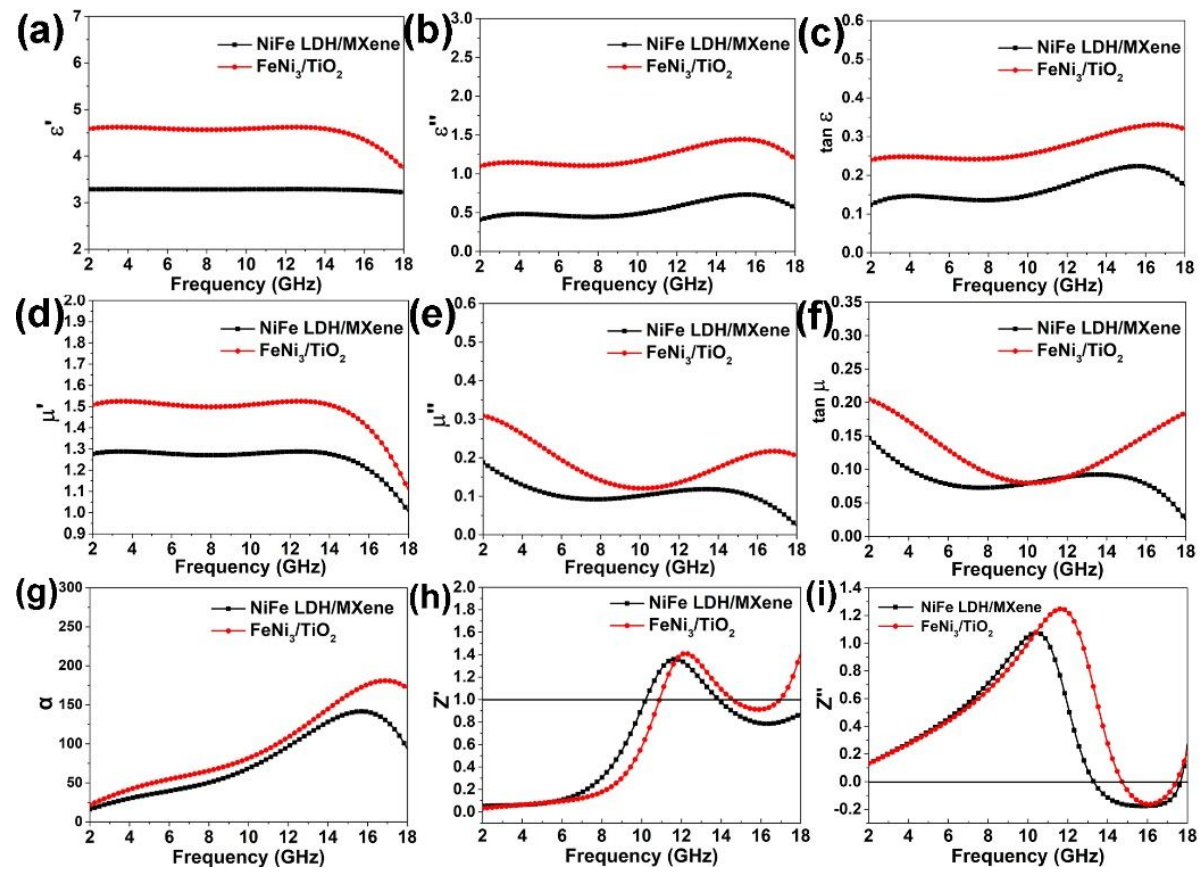

Figure S11 (a-f) $\varepsilon^{\prime}, \varepsilon^{\prime \prime}$ and $\tan \varepsilon$ as well as $\mu^{\prime}, \mu^{\prime \prime}$ and $\tan \mu$ of the NiFe LDH/MXene and $\mathrm{FeNi}_{3} / \mathrm{TiO}_{2}$. (g-i) Attenuation constant $(\alpha)$, real $\left(\mathrm{Z}^{\prime}\right)$ and imaginary $\left(\mathrm{Z}^{\prime \prime}\right)$ impedance of the NiFe $\mathrm{LDH} / \mathrm{MXene}$ and $\mathrm{FeNi}_{3} / \mathrm{TiO}_{2}$. 

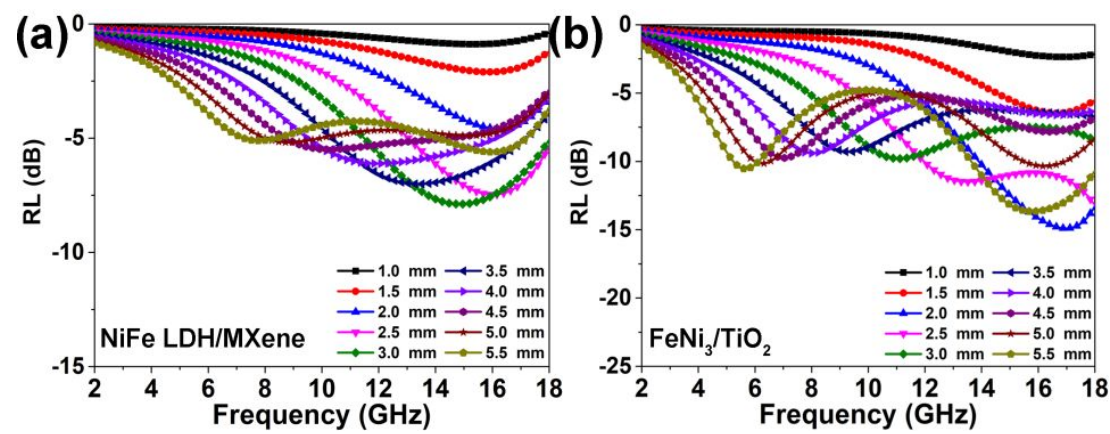

Figure S12. (a-b) RL calculated for the $\mathrm{NiFe} \mathrm{LDH} / \mathrm{MXene}$ and $\mathrm{FeNi}_{3} / \mathrm{TiO}_{2}$ samples. 